Boise State University

ScholarWorks

Biology Faculty Publications and Presentations

Department of Biological Sciences

4-1-2016

\title{
Variable Shifts in the Autumn Migration Phenology of Soaring Birds in Southern Spain
}

Micah N. Scholer

Boise State University

Beatriz Martín

Fundación Migres

Miguel Ferrer

Boise State University

Alejandro Onrubia

Fundación Migres

Marc J. Bechard

Boise State University

See next page for additional authors 
Authors

Micah N. Scholer, Beatriz Martín, Miguel Ferrer, Alejandro Onrubia, Marc J. Bechard, Greg S. Kaltenecker, and Jay D. Carlisle 


\section{Variable shifts in the autumn migration phenology of soaring birds in southern Spain}

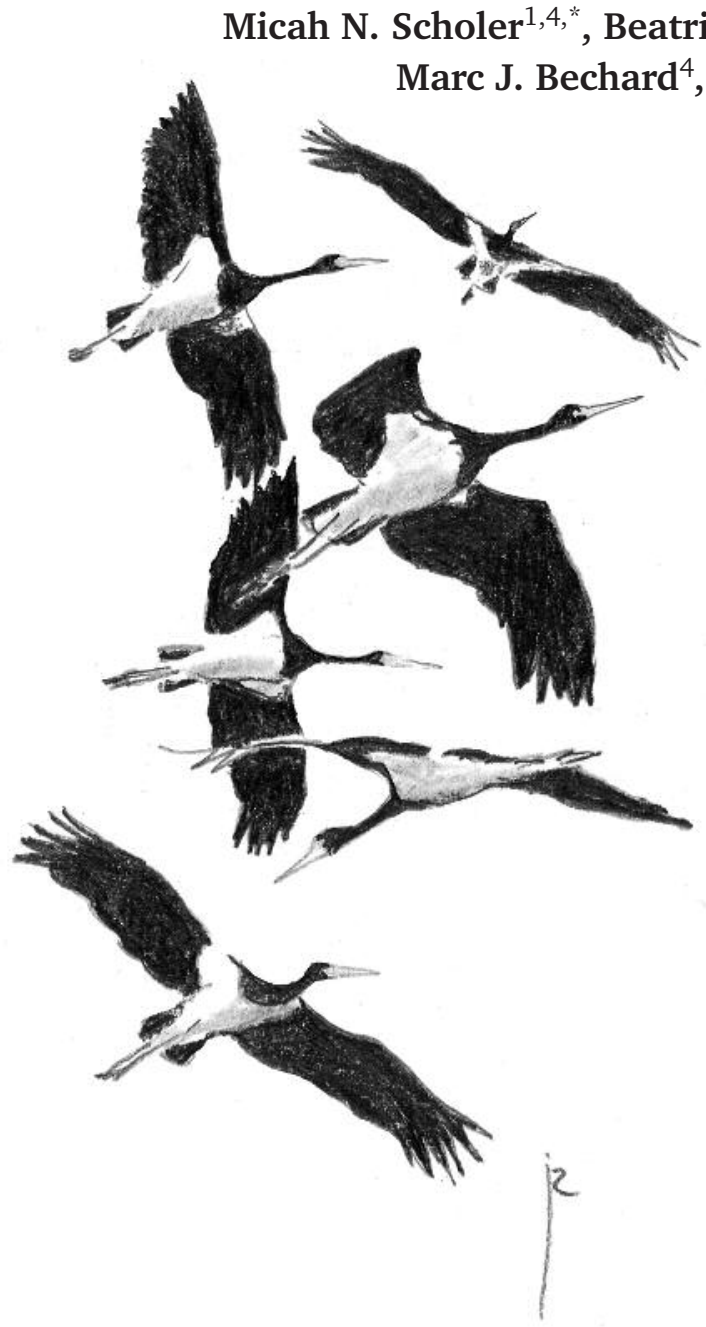

Scholer M.N., Martín B., Ferrer M., Onrubia A., Bechard M.J., Kaltenecker G.S. \& Carlisle J.D. 2016. Variable shifts in the autumn migration phenology of soaring birds in southern Spain. Ardea 104: 83-93. doi:10.5253/arde.v104i1.a7

While alteration of the migratory habits of birds is widely regarded as one of the most evident ecological effects of climate change, studies reporting shifts in migration phenology for long-lived, long-distance migrants have been few. Using time series of count data collected in southern Spain during autumn migration, we examined the magnitude and direction of phenological shifts for six common species of soaring birds. Many current methods for investigating phenological change rely on continuous data sets; however, these data may be unavailable for a variety of reasons. We used a cross-correlation analysis, which allowed us to compare recent data on the timing of migration from 1999-2011 to a historic data set collected during 1976-1977. The direction of phenological shifts for autumn migration was species-specific. White Storks Ciconia ciconia and Black Kites Milvus migrans appeared to have delayed passage, Black Storks Ciconia nigra and European Honey Buzzards Pernis apivorus have advanced their migratory timing, and we found no clear phenological change for Short-toed Eagles Circaetus gallicus or Booted Eagles Hieraaetus pennatus.

Key words: Europe, long-distance migrants, raptors, storks, Strait of Gibraltar, timing of autumn migration

${ }^{1}$ Intermountain Bird Observatory, Department of Biological Sciences, Boise State University, 1910 University Dr., Boise, ID 83725, USA; ${ }^{2}$ Fundación Migres, N-340, Km. 96.2. Huerta Grande, Pelayo E-11390 Algeciras, Cádiz, Spain; ${ }^{3}$ Departamento de Etología y Conservación de la Biodiversidad. Estación Biológica de Doñana, CSIC. C/ Américo Vespuccio, s/n. Sevilla E-41092, Spain; ${ }^{4}$ Department of Biological Sciences, Boise State University, 1910 University Dr., Boise, ID 83725, USA;

*corresponding author (micahscholer@gmail.com)
The biological consequences of climate change for birds are now well documented for a wide range of taxa and species (Møller et al. 2010). In particular, studies addressing avian migration behaviour in response to these changes have grown rapidly in recent decades (Gordo 2007, Newton 2008). An estimated 2600 bird species of 141 families undergo some type of seasonal migration (Cox 2010). The capacity of these diverse migrants to adjust to altered environmental conditions is therefore likely to vary across geographic regions and depending on the species' life history strategy. A complete picture of the impact of climate change on bird migration therefore necessitates understanding how species with varied life history traits and distributions are adjusting their migratory behaviour.
Although many studies report a trend towards earlier spring arrival in migratory birds, our understanding of how climate change influences other parts of the annual cycle remains less clear (Jenni \& Kéry 2003, Gordo 2007, Cox 2010). For example, in contrast to spring migration, fewer data exist for shifts in autumn migration with some species showing advances in their migration phenology while others appear to be experiencing delays (Gordo 2007). Furthermore, the majority of these studies have focused on short-lived passerines as model species (Jenni \& Kéry 2003, Mills 2005, Jonzén et al. 2006, Tøttrup et al. 2006), yet our understanding of the effects of climate change on large, long-lived species of soaring birds, such as raptors and storks, remains largely unexplored (Lehikoinen \& Sparks 2010). 


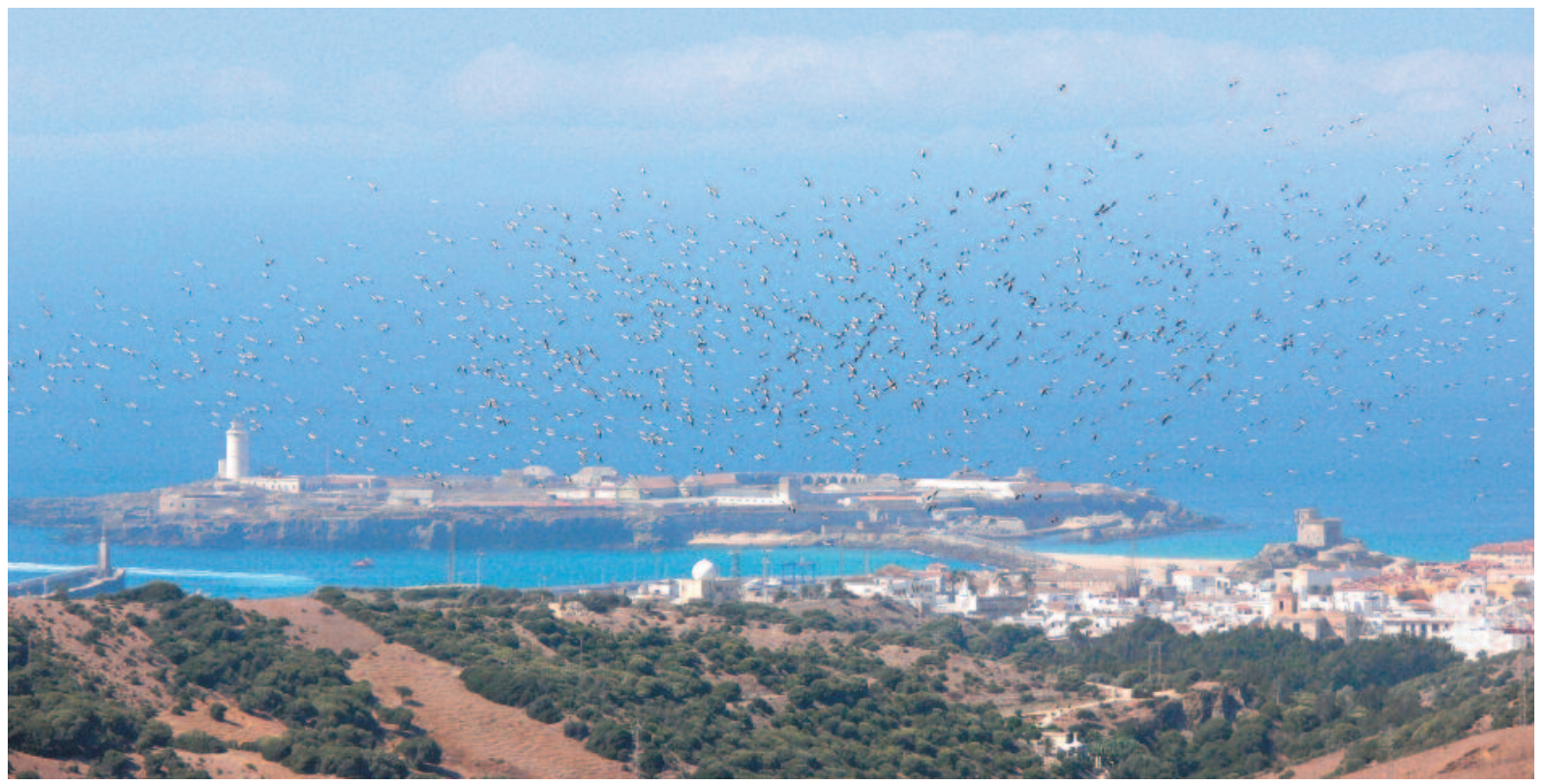

Photo 1. A flock of White Storks above Tarifa on its way to cross the Strait of Gibraltar (photo: Alejandro Onrubia).

In this study, we examine changes in autumn migration phenology for a suite of soaring birds. Data collected from long-term, standardized monitoring programs along migratory routes are perhaps the best data available for studying phenological trends and various modelling techniques have been designed to characterize changes in bird migration (see Knudsen et al. 2007 for a review). In this study, we take advantage of the standardized monitoring of soaring birds in southern Spain by comparing annual time series of count data from a historical data set 1976-1977 and from 1999-2011. We examine the magnitude and direction of phenological shifts using cross-correlation analysis (Cassel et al. 2000) by comparing the synchrony of count data between three different time periods for each study species: 1970s-2000s, 1970s2010s, and 2000s-2010s. Cross correlation analysis is appealing because it allows for comparisons between years, regardless of whether data were collected during the period separating each time series. Such 'snap shot' approaches can be useful in cases where observatories are unable to conduct or use count data from a particular year (i.e. incomplete time series for financial or logistical reasons or due to incongruities in data collection) or only a historical data set exists for long term comparisons, such as in our study.

The few studies that have examined autumn migration of European soaring birds report that most species are advancing their migration (Filippi-Codacciuoni et al. 2010, Lehikoinen 2011, Jaffré et al. 2013). We therefore predicted that soaring birds would advance their passage date and that advancements would be most pronounced between the 1970s and 2000s. We based this assumption on trends in global surface temperatures that suggest the majority of climate warming took place before 2000 (ICPP 2007, Solomon et al. 2010). Within an ecological context, advancement of autumn migration is only expected if an early departure is associated with benefits. For example, arriving earlier would allow birds to locate optimal winter territories resulting in better body condition for spring migration (Newton 2008). There is also evidence suggesting that single brooded species, such as the soaring birds we studied, may advance the timing of autumn migration when spring migration is also advanced (Jenni \& Kéry 2003, Jaffré et al. 2013).

\section{METHODS}

\section{Study area}

We conducted our study in the area of the Strait of Gibraltar (hereafter the Strait) located in the southern extreme of Spain. It is here that the shortest distance between continental Europe and North Africa is found. Hence the region acts as an obligatory crossing point for the majority of soaring birds migrating from Western Europe. Movements of soaring birds crossing the Strait are strongly governed by the prevailing weather conditions with westerly winds giving rise to 
higher concentrations of birds following the Mediterranean coast and easterly winds resulting in concentrations of birds following the Atlantic coast (Bernis 1980). Furthermore, the migration routes of different species vary, making the Mediterranean side optimal for viewing some species while others concentrate further west along the Atlantic Ocean. We therefore collected count data for migratory soaring birds at two different observatories positioned near the coast of the Strait: Algarrobo, 54.7'37"S, 6.25'21'W, which is situated near the town of Algeciras along the Mediterranean, and Cazalla, 54.10'4"S, 6.33'30"W, located closer to the Atlantic coast (Figure 1).

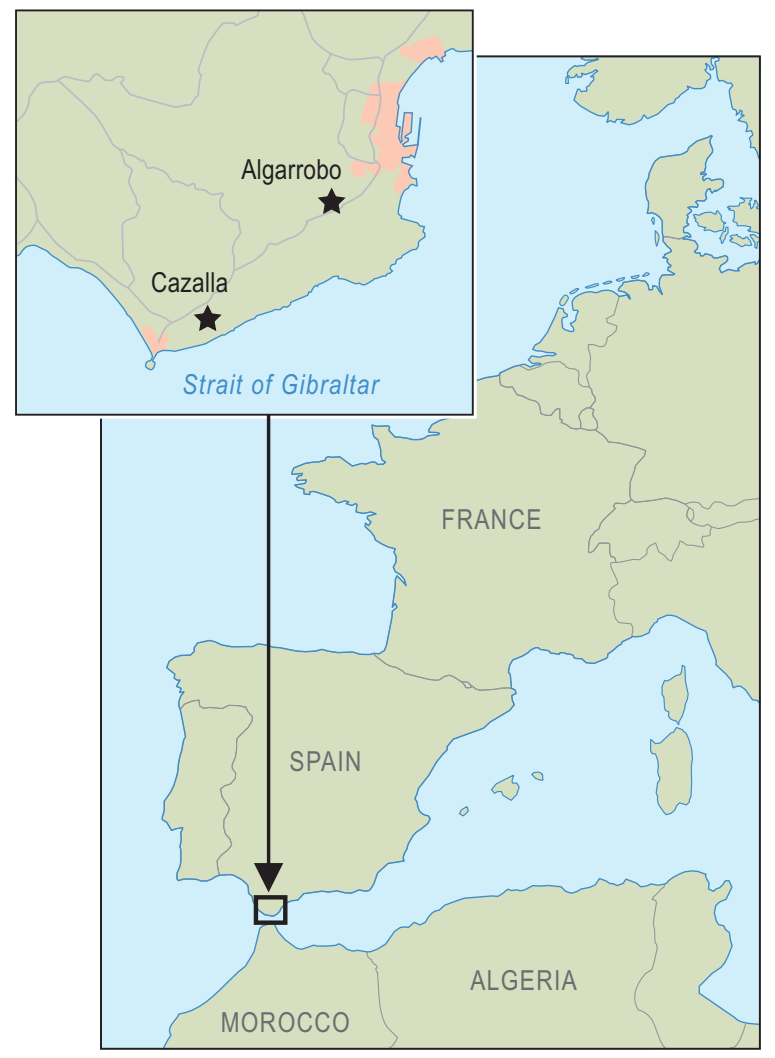

Figure 1. Location of the two observatories in southern Spain where migrations counts of soaring birds were conducted.

\section{Study species and data collection}

We used count data for soaring birds during autumn migration from a baseline dataset collected in 1976 and 1977 (Bernis 1980) and a long-term dataset from 1999-2011. For all years, autumn migration counts were conducted daily from approximately 8:00-17:00, Central European Time, beginning in mid-July and ending in mid-October. In 1976-1977, counts were carried out at both observatories by a minimum of four volunteers with at least one of the volunteers at each site being a trained ornithologist (Bernis 1980). Based on this study a similar methodology detailed in Barrios and Doval (2007) allowed for standardized surveys of soaring birds at both Algarrobo and Cazalla from 1999 until present. Soaring birds will often delay crossing the Strait under suboptimal weather conditions (e.g. high winds, rain or low visibility between Spain and Africa); waiting along the coast until conditions improve. Therefore, cardinal values were assigned to all birds detected for their direction of origin and destination. We only considered individuals for analysis if they were assigned a southern trajectory (i.e. indicating they were likely going to attempt to cross the Strait) to minimize the possibility of over-estimating the number of birds migrating. Counts were not conducted on 72 of 1009 count days from 1999-2011 because of persistent precipitation or wind speeds that exceeded 6 Beaufort.

Thirty species of soaring birds can be regularly counted in the Strait each year. For our analysis, we considered species that 1 ) could easily and accurately be identified by observers and 2) were most abundant during the autumn migration. We did this to both minimize possible differences in the count data introduced by observer bias as well as maximize our effective sample size. We included White Stork Ciconia ciconia, Black Stork Ciconia nigra, Short-toed Eagle Circaetus gallicus, Booted Eagle Hieraaetus pennatus, Black Kite Milvus migrans, and European Honey Buzzard Pernis apivorus (hereafter Honey Buzzard). This list is representative of a suite of long-lived and large-bodied European breeding species which annually migrate from Western Europe to south of the Sahara desert.

\section{Modelling shifts in phenology}

To assess whether phenological timing differed between years, we analysed time series for soaring birds counted from 1976-1977 and 1999-2011. We first pooled data from both observatories for all birds with a southern trajectory. We then created a relative frequency distribution of species abundance by dividing daily totals for each species by the total number of birds observed for that species during the season. For comparing years, we identified three time periods of interest that we refer to as the 1970s, 2000s, and 2010s time series, which were calculated by averaging counts between adjacent years for 1976-1977, 1999-2000, and 2010-2011, respectively. To further reduce noise and irregularities we applied a Gaussian kernel smoothing technique to the frequency distribution. Kernel smoothing uses a bandwidth parameter to estimate the optimal degree of 
smoothing for a kernel density estimate. Larger bandwidths create smoother estimates that may obscure local features of the distribution while small bandwidths may lead to spurious estimates caused by 'spikes' in the density estimate (Wand \& Jones 1995). We used the function dpill in the $R$ package KernSmooth (Wand 2014) to select the optimal bandwidth for each year and species. This 'direct plug' method calculates unknown bandwidth parameters with standard, normal density kernel estimators using a least squares method to fit blocks of data. Mallow's $C_{p}$ is used to select the number of blocks of data used (Wand \& Jones 1995). Our motivation for smoothing was to allow for 1) missing days in our dataset due to inclement weather conditions, 2) variation in sampling effort, and 3) a more flexible interpretation of between-year variation in the phenological distribution (Chatfield 2003, Knudsen et al. 2007). The latter is of particular importance when dealing with soaring bird migration. As some species display bimodal phenological distributions attributed to the difference in passage of adults and juveniles or males and females, analysis of raw data makes it difficult to identify a single overall shift between two relative frequency distributions (Knudsen et al. 2007). Assuming that the smoothed count data was a proxy for the species' phenology, we calculated separate time series for each year and for each species using the script itall.R (Shumway \& Stoffer 2006).

We used a cross-correlation analysis to explore the spatial relationship between two time series $x$ and $y$ as described by Cassel et al. (2000) using the cross-covariance function

$$
C_{x y}(h)=\frac{1}{n(h)} \sum_{i=1}^{n(h)}\left(x_{i+h}-\bar{x}\right)\left(y_{i}-\bar{y}\right)
$$

where $n(h)$ is the number of pairs of sample points at a lag distance $h$ apart, $x_{i+h}$ and $y_{i}$ are measurements $x$ and $y$ at locations $i+h$ and $i$, respectively, and $i$ and $h$ are vectors. The cross correlation function $\gamma_{x y}(h)$ was used to visualize the spatial correlation between our three time periods of interest and was calculated as follows:

$$
\gamma_{x y}(h)=C_{x y}(h)\left(\sigma_{x} \sigma_{y}\right)^{-1}
$$

with the standard deviations $\sigma_{x}$ and $\sigma_{y}$ of $x$ and $y$, respectively (Cassel et al. 2000).

Using the $c c f$ function in itall.R (Shumway \& Stoffer 2006), we explored the cross correlation between paired daily abundance (percentage) estimates for soaring birds by setting the most historic time period as a reference and shifting the other temporally until the

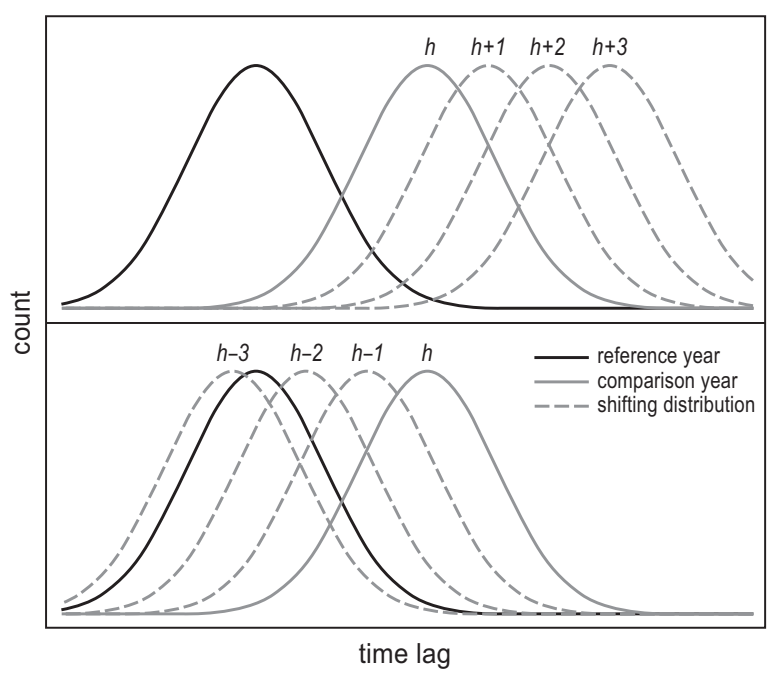

Figure 2. This scheme demonstrates our use of the cross correlation function to assess shifts in migration timing between two years. The frequency distribution of a comparison year is shifted ahead (top panel) and behind (bottom panel) a reference year by a time lag distance $h$ (e.g. weeks, days, hours) until the maximum overlap between distributions is found. In this case, shifting the distribution by a lag distance of $h-3$ results in the most parsimonious match, suggesting that migration has advanced in relation to the reference year.

most parsimonious correlations between abundances were found (Figure 2). Our goal was to determine the correlation between distribution counts of adjacent years and if the degree of coupling (synchronous or lagged) was constant over the last decade. In other words, we sought to identify whether counts from one year 'peaked' at a different time(s) and, if true, how far ahead or behind these peaks lagged in reference to the historic time period. To assess if phenological shifts in migration have occurred in the past four decades and whether the magnitude of those shifts differed between time periods, we estimated cross-correlation functions (CCFs) for lags up to \pm 20 days for time series comparisons between the 1970s-2000s, 1970s-2010s, and 2000s-2010s ( $n=83$ days for each comparison). As high inter-annual variation may mask changes in the phenology, we also compared smoothed time series for 1976-1977, 1999-2000, and 2010-2011 to explore how variation in phenology between consecutive years compares to analysis of longer time frames. Using Bartlett's method, we determined the statistical significance of cross-correlations time lags at a threshold of $\alpha=0.05$ for $C C F>2 /(\sqrt{ } n)$ where $n$ is the number of data points in the time series (Chatfield 2003). All analyses were carried out in R v. 3.0.3 (R Development Core Team 2014). 

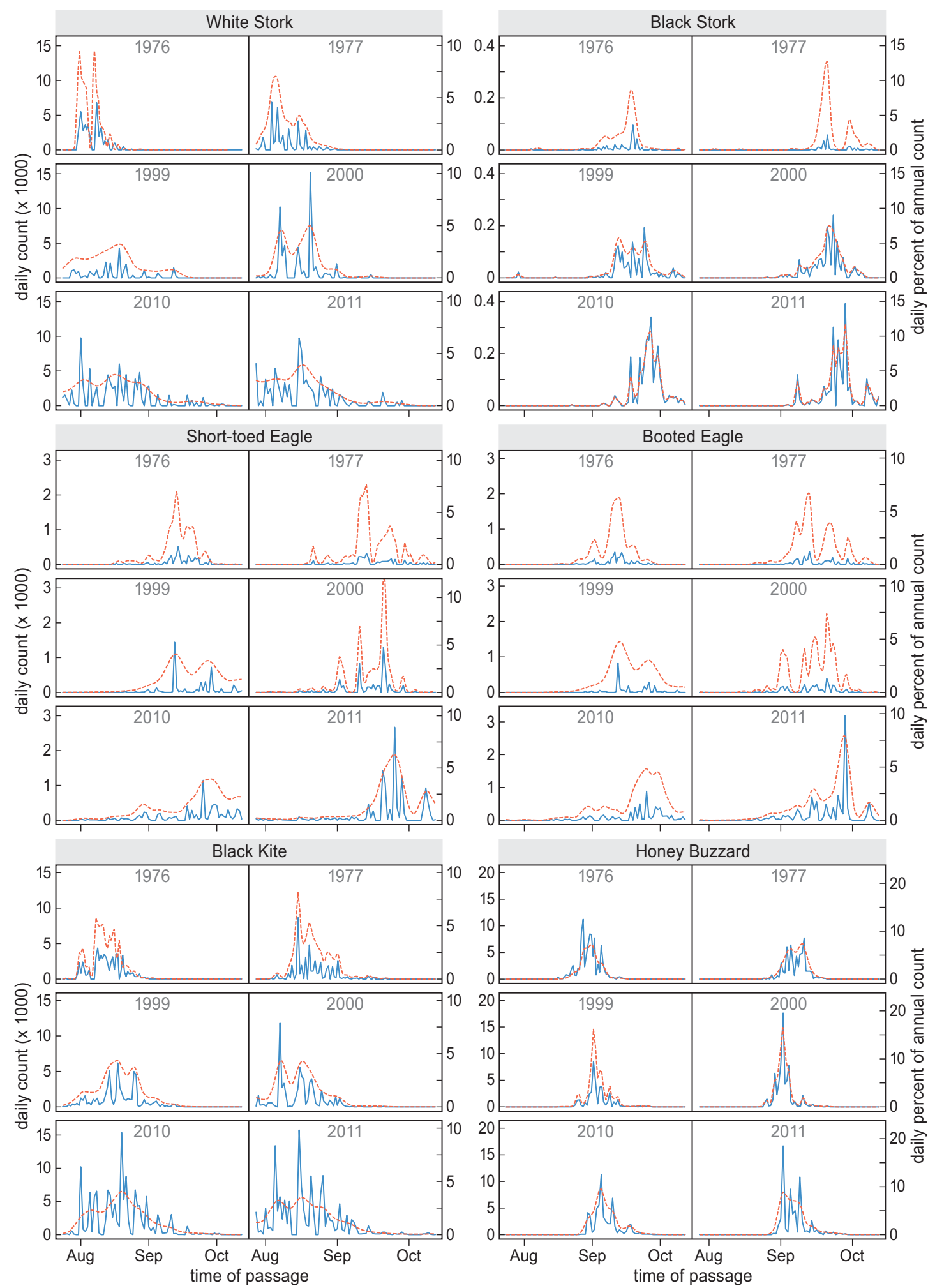

Figure 3. Frequency distributions for the autumn migration timing of White Stork, Black Stork, Short-toed Eagle, Booted Eagle, Black Kite, and Honey Buzzard crossing the Strait of Gibraltar. Solid lines show the total number of soaring birds counted daily (y-axis on left-hand side). The smoothed function for the daily percent passage of birds based on annual totals is given by the dashed line (y-axis right-hand side). 


\section{RESULTS}

Between 1976 and 2011, more than 3.5 million birds were counted crossing the Strait of Gibraltar. Figure 3 shows the frequency distributions of the daily passage of soaring birds for each time period used in the final analysis (1976/1977, 1999/2000, and 2010/2011). Figure 4 demonstrates long term shifts in the autumn migration phenology for each of the six study species. Figure 5 illustrates the inter-period variation in migration timing calculated from adjacent years.

\section{Shifts in migration phenology: comparisons between 1970s, 2000s and 2010s}

The largest shift in the phenology of migration was observed in the White Stork (Figure 4). Between 1976 and 2010 White Storks delayed their autumn migration by 15 days. Changes in phenology were not constant between time periods (Table 1). White Storks strongly delayed their migration during the first period (1970s-2000s, time lag $h=-9$ days) but slightly advanced their migration during the second period (2000s-2010s, $h=+3$ days). A similar pattern was observed for the Black Kite. Over the whole study period Black Kites delayed their autumn migration by four days, but this delay was only pronounced for the first period (1970s-2000s, $h=-4$ days) as no phenological shift was observed for the second period (2000s-2010s, $h=0$ ).

In contrast, the Black Stork advanced autumn migration by nine days between 1976 and 2011 ( $h=$ +6 and +3 days for 1970s-2000s and 2000s-2010s, respectively); a stable change in phenology across time periods (Figure 4, Table 1). Similarly, Honey Buzzards advanced their autumn migration over the whole study period (1970s-2010s, $h=+3$ days), but this advance was more marked during the first time period compared to the 2000s-2010s time period (Table 1).
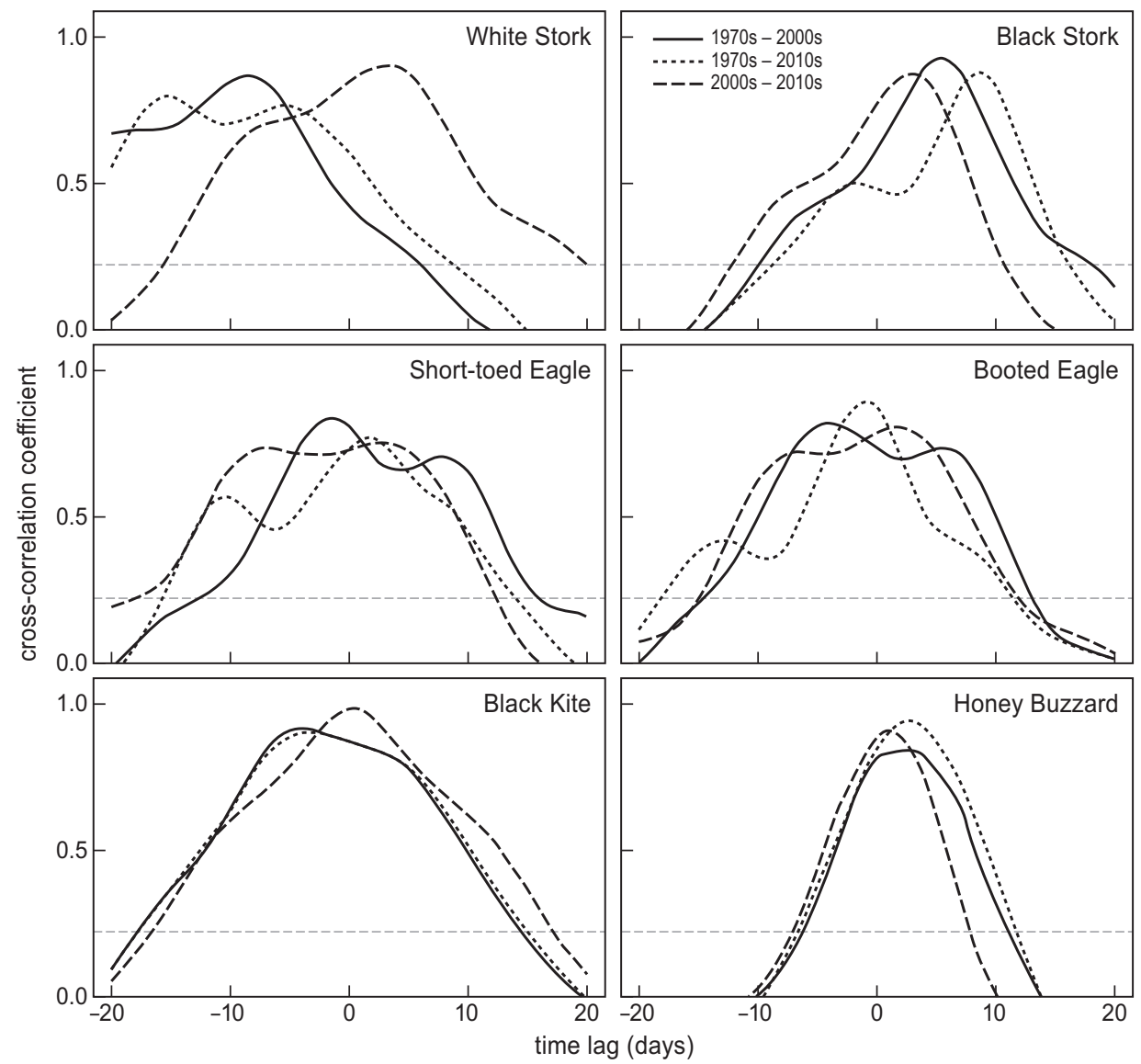

Figure 4. Temporal cross-correlation functions of shifts in autumn migration phenology for White Stork, Black Stork, Short-toed Eagle, Booted Eagle, Black Kite, and Honey Buzzard at the Strait of Gibraltar, Spain. Positive values indicate advancement in migration timing relative to a given reference year while negative values indicate a delay. The gray, dashed line represents Bartlett's line, which needs to be exceeded for correlations to be considered significant. 
Honey Buzzards displayed the most concentrated migration of the soaring birds we studied with $80-89 \%$ of the total birds counted each year passing within a two-week period (Figure 3).

Table 1. Summary of the annual rate of change ( $\Delta$ days/year relative to a reference time period) and the peak time lag in days $(h)$ of soaring bird migration phenology. The CCF represents the values of the cross-correlation coefficient for each lag. Comparisons are of count data for migrating birds from the 1970s, 2000s, and 2010s. All peak lags were considered statistically significant at $P<0.001$ using Bartlett's method.

\begin{tabular}{|c|c|c|c|c|c|c|c|c|c|}
\hline \multirow[b]{3}{*}{ Species } & \multicolumn{9}{|c|}{ Time series comparisons } \\
\hline & \multicolumn{3}{|c|}{ 1970s-2010s } & \multicolumn{3}{|c|}{ 1970s-2000s } & \multicolumn{3}{|c|}{$2000 s-2010 s$} \\
\hline & $\Delta$ days/year & $h$ & $C C F$ & $\Delta$ days/year & $h$ & $C C F$ & $\Delta$ days/year & $h$ & $C C F$ \\
\hline White Stork Ciconia ciconia & -0.417 & -15 & 0.795 & -0.375 & -9 & 0.846 & 0.231 & +3 & 0.903 \\
\hline Black Stork Ciconia negra & 0.250 & +9 & 0.876 & 0.250 & +6 & 0.923 & 0.231 & +3 & 0.873 \\
\hline Short-toed Eagle Circaetus gallicus & 0.056 & +2 & 0.771 & -0.042 & -1 & 0.833 & 0.231 & +3 & 0.750 \\
\hline Booted Eagle Hieraaetus pennatus & 0.027 & -1 & 0.898 & -0.167 & -4 & 0.819 & 0.150 & +2 & 0.804 \\
\hline Black Kite Milvus migrans & -0.111 & -4 & 0.897 & -0.167 & -4 & 0.917 & 0.000 & 0 & 0.990 \\
\hline Honey Buzzard Pernis apivorus & 0.083 & +3 & 0.946 & 0.125 & +3 & 0.842 & 0.077 & +1 & 0.912 \\
\hline
\end{tabular}
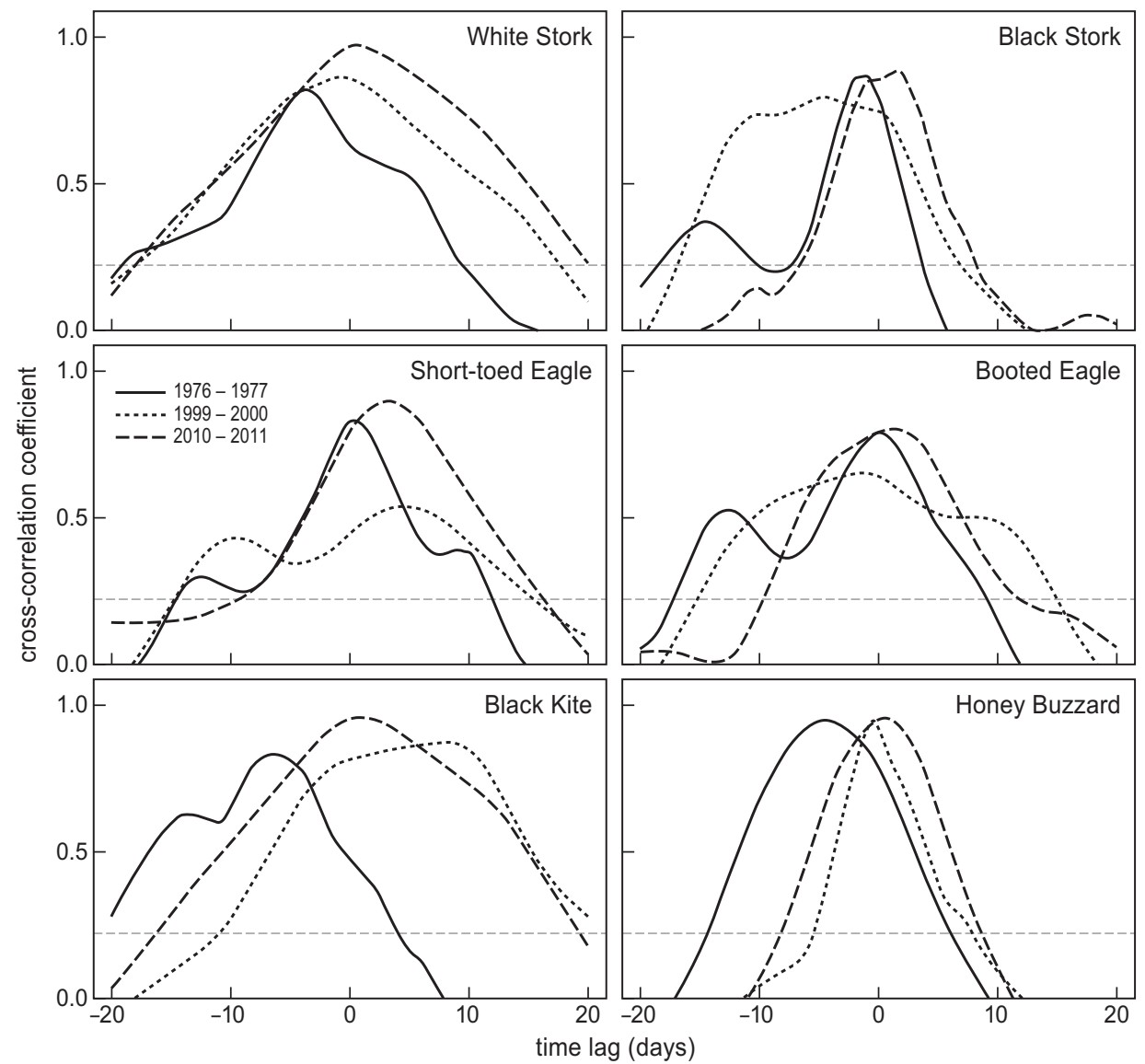

Figure 5. Temporal cross-correlation functions of inter-period variation between to 1976/1977, 1999/2000, and 2010/2011for six species of soaring birds observed in the Strait of Gibraltar, Spain, during autumn migration. The gray, dashed line is Bartlett's line above which coefficients are considered significantly different from 0 at $P<0.05$. 
We found no clear phenological shifts for either eagle species. Short-toed Eagles showed a slight delay in their autumn migration during the first period (1970s-2000s, $h=-1$ days), a moderate advancement during the second period (2000s, 2010s, $h=+3$ days), and resulting slight advancement over the whole study period (Figure 4, Table 1). Likewise, timing of migration was highly variable for Booted Eagles, which showed a moderate delay during the first period (1970s-2000s, $h=-4$ days), a slight advancement during the 2000s-2010s ( $h=+2$ days) and no overall change in migration timing between the 1970s-2010s (Table 1). Cross-correlation coefficients estimated for peak lags were always statistically significant for all species (Figure 4).

\section{Inter-period variation}

Time lags for adjacent years tended to be smaller than those identified by comparisons between the 1970s, 2000s, and 2010s (Table 1, Figures 4 \& 5). For many species, cross-correlation coefficients were often highest at or near a lag distance of 0 days (Figure 5). Exceptions to this were formed by Black Storks and Black Kites for comparisons between 1999 and 2000 and Honey Buzzards between 1976 and1977. Here, shifts in migration timing were of higher magnitude ( $h=-12,+8$, and -5 days for the three species, respectively) and in the opposite direction than those identified for peak lags over larger time periods. Shorttoed Eagles also showed higher variation between subsequent years for both 1999-2000 and 2010-2011 comparisons.

\section{DISCUSSION}

Identifying shifts in migration phenology is crucial for our understanding of how birds with different life histories will persist under a scenario of continued climate change. Previous studies have focused on first and last appearance dates, mean or median dates and different percentiles to characterize migration phenology (Knudsen et al. 2009). However, these techniques fail to consider the temporal distribution of migration count data, in particular the bimodal character of such time series data. Cross-correlation analysis of passage dates accounts for this non-regularity in time series data when calculating phenological shifts, and, to the best of our knowledge, our study represents one of the first to use time series and cross-correlation analysis to explicitly model bird phenology for autumn migration. This approach also allows for a 'snap shot' analysis of non-continuous series of data, such as the ones we utilized for soaring birds crossing the Strait.

Over the 36 year time period we considered, phenology advanced for two species whereas two species showed delayed passages and two species displayed no clear change. During this same time, global surface air temperature increased and the majority of this warming occurred in the years between the mid-1970s and the late 1990s (IPCC 2007). As in previous studies, these data provide no direct evidence that migratory shifts occurred as a result of climate warming. However, findings from the current study are broadly comparable to numerous works that have noted correlations between shifting migration phenology and climate change (Gordo 2007). The variable responses we observed in autumn passage timing supports previous heterogeneous findings on migratory shifts in postnuptial movements for other species (Jenni \& Kéry 2003, Thorup et al. 2007, Filippi-Codacciuoni et al. 2010, Van Buskirk 2012). Other researchers have noted distinct increases in temperature for Western Europe during the latter part of the 20th century, followed by a period of relative cooling (Jaffré et al. 2013) and these trends are in concordance with changes in temperature across the northern hemisphere (IPCC 2007, Lawrimore et al. 2011). Perhaps not surprisingly then, the shifts we detected generally occurred between 1970s-2000s whereas no or only slight changes were observed in 2000s-2010s (Figure 4). White Storks and Black Kites both showed a moderate to strong delay in migratory timing for the 1970s-2000s and a slight advancement to no change between 2000s-2010s (Table 1). Honey Buzzards also showed a nearly twofold increase in the rate of migratory change between 1970s-2000s compared to the 2000s-2010s. Many researchers have pointed to the importance of long term (i.e. $>10$ years) studies in revealing phenological trends (Knudsen et al. 2007, Lehikoinen \& Sparks 2010, Kerr \& Dobroski 2013). Our results are in accordance with these statements and suggest that an analysis based on data from the last decade alone may not be a long enough time frame to detect shifts in phenology.

While most of the soaring bird species we studied appeared to have experienced shifts in their migration phenology, the direction of those shifts was speciesspecific. Black Storks and Honey Buzzards both advanced their migratory timing. Filippi-Codacciuoni et al. (2010) reported an advance in migration of 3.39 days for Honey Buzzards. Our estimates of an advance in passage timing of 3 days for this species is in agreement with this observation and supports other studies which report advancing passage dates in European 


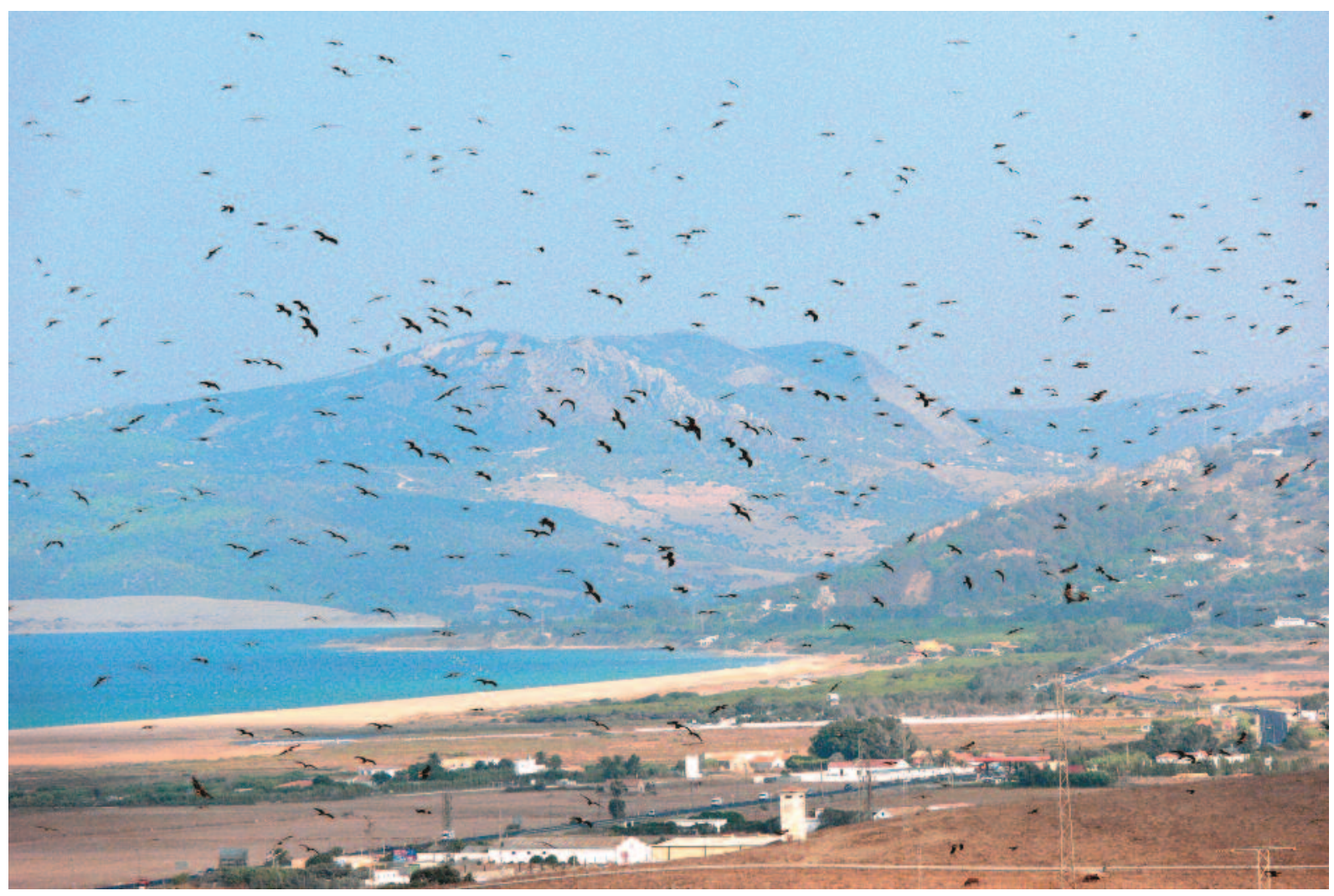

Photo 2. Black Kites gather before making the crossing to Morocco (photo Alejandro Onrubia).

short-distance soaring birds (Jaffré et al. 2013). The most common explanation for earlier passage timing is that it results from an earlier arrival to breeding areas in spring without a change in the length of the breeding season and, consequently, an advance in the timing of all events from arrival to breeding to departure (Lehikoinen et al. 2004, Gordo 2007). It has also been proposed that a shortening of the distance between wintering and breeding areas could lead to a strong advancement in passage timing (Visser et al. 2009).

Contrary to our prediction, White Storks and Black Kites delayed their passage. Late autumn passage could suggest that White Storks and Black Kites are benefiting from an increased amount of time spent at or near the breeding area, perhaps as a result of an increased number of reproductive attempts or at least an increased opportunity to re-nest after early season nest failures. Jaffré et al. (2013) found support for an overall lengthening of the breeding season in soaring birds and this lengthening was correlated to increasing spring temperatures in Western Europe (Lawrimore et al. 2011). There is evidence of advances in the spring migration of long-distance migratory raptors (Van Buskirk 2012). In the case of White Storks, advances in spring migration have also been found (Ptaszky et al. 2003, Vaitkuviene et al. 2015) and the number of overwintering birds in southern Europe increased during the past three decades (Molina \& Del Moral 2005). It therefore seems reasonable to suggest that the observed delay in passage for White Storks and Black Kites may be a result of an increased length in the breeding season for these species throughout their range.

For data collected during the 2000s, the distribution of migration counts for White Storks and Black Kites appears incomplete for the earliest phase of the migration. For example, during 2010 and 2011, 1247 and 6087 White Stork were counted during the first day of the migration census, respectively (Figure 3). Similarly, 3468 Black Kites in were observed crossing the Strait on the first day of migration counts in 2011. Thus, these species may also have advanced their migration and the apparent delay in passage is simply an artefact of counts beginning too late in the season. Results of these shifts should therefore be interpreted with caution. Regardless of the causal mechanism, there is a clear need for bird observatories monitoring migration to extend the period over which counts are conducted in order to capture the entire migratory period. In the 
case of White Storks and Black Kites, our data indicated that autumn migration counts should start at least two weeks earlier than in 1976 to capture the complete migration period for these species. Therefore, White Storks and Black Kites not only delayed their migration but they also appear to have lengthened the total migration period, although we cannot detect an earlier onset of autumn migration because of the lack of data. A likely explanation is that lengthening of the migration period may be related to population increases for these species. European populations of White Storks declined from 1976 to 1999 (Birdlife International 2004) but a strong recovery took place from 2000 to 2011. In particular, northern populations of White Storks, which migrate later than southern populations, have increased substantially over the last decade and may be responsible for the observed delay in migration (B. Martin unpubl. data). Similarly, populations of Black Kites declined across much of Europe by nearly $30 \%$ between 1970 and 2000, but have since stabilized and may have begun to increase (Birdlife International 2004).

Regional weather conditions have a strong influence on the flight speed and performance of soaring birds (Vaitkuviene et al. 2015, Vansteelant et al. 2015). Local conditions in the Strait also affect the migration phenology for all species, especially during periods of sustained high winds when birds are prevented from crossing to Africa. For example, meteorological events related to deteriorating survival and flight conditions at the breeding area may influence departure timing of soaring birds while weather conditions encountered en route to bottleneck sites can modulate the timing of their passage at such locations (Shamoun-Baranes et al. 2006). Thus, while our phenological trends from consecutive years seem to support the hypothesis that lags are due to a changing trend in migration patterns for some species, results for species where inter-period variation was high are less certain. Short-toed Eagles, and to a lesser extent Black Stork, Black Kite, and Honey Buzzard showed variation in the strength and direction of inter-period shifts. This might indicate a greater influence of local weather conditions or those further north en route to the Strait in determining the migration timing for these species. Whatever the cause, results from these species, in particular the Short-toed Eagle, should be interpreted with caution.

Little work has been conducted on long-lived species such as storks and raptors which may live to greater than 20 years of age in the wild (Mebs \& Schmidt 2006). As all long-distance soaring birds are also generally long-lived, their ability to learn and therefore adjust their behaviour may be greater than smaller birds with shorter life expectancies. Hence, their handicap in being able to detect changing climatic cues may be offset by their capacity for phenotypic adjustment based on accumulated learned experiences during migration. Indeed, in a study of Black Kites, Sergio et al. (2014) demonstrate that migration behaviour changes throughout the life of a migrant through gradual individual improvements to migration routes and flight technique. Our findings on long-term trends in the phenology of soaring migrants add to the growing body of literature indicating that migrants with varied life history characteristics are shifting their migration patterns. Other migration count-sites or bird observatories lacking continuous times series of count data may consider adopting a similar cross-correlation analysis approach to explore changes in phenological trends.

\section{ACKNOWLEDGEMENTS}

Our thanks and gratitude goes out to the many people who took part in conducting the migration surveys throughout the Strait of Gibraltar. This study was funded by grants of the Regional Ministry for Environment of Andalusia and The Board of Fundación Migres. We are grateful to Dr. Mark Rudin for making possible this international collaboration between the Intermountain Bird Observatory and Fundación Migres. Comments from R. Klaassen, W. Vansteelant, and an anonymous reviewer greatly improved the quality of this manuscript.

\section{REFERENCES}

Barrios L. \& Doval G. 2007. El Programa Migres de aves planeadoras: datos actualizados a los años 2005 y 2006. Almoraima 35: 77-85.

Bernis F. 1980. La migración de las aves en el Estrecho de Gibraltar (Epoca Posnupcial). Vol.1. Aves Planeadoras. Universidad Complutense, Madrid.

BirdLife International 2004. Birds in Europe: population estimates, trends and conservation status. BirdLife Conservation Series no. 12, Cambridge.

Cassel D.K., Wendroth O. \& Nielsen D.R. 2000. Assessing spatial variability in an agricultural experiment station field: opportunities arising from spatial dependence. Agron. J. 92: 706-714.

Chatfield C. 2003. The analysis of time series: and introduction. Chapman and Hall, London.

Cox G.W. 2010. Bird migration and global change. Island Press, Washington.

Filippi-Codacciuoni O., Moussus Z.P., Urcun J.P. \& Jiguet F. 2010. Advanced departure dates in long-distance migratory raptors. J. Ornithol. 151: 687-694.

Gordo O. 2007. Why are bird migration dates shifting? A review of weather and climate effects on avian migration phenology. Clim. Res. 35: 37-58. 
IPCC. 2007. Climate change 2007: the physical science basis. Cambridge University Press, Cambridge.

Jaffré M., Beaugrand G., Goberville É., Jiguet F., Kjellén N., Troost G., Dubois P.J., Leprêtre A. \& Lukzak C. 2013. Longterm phenological shifts in raptor migration and climate. PLoS ONE 8:e79112.

Jenni L. \& Kéry M. 2003. Timing of autumn bird migration under climate change: advances in long-distance migrants, delays in short-distance migrants. Proc. R. Soc. Lond. B 270: 1467-1471.

Jonzén N., Lindén A., Ergon T., Knudsen E., Vik J.O., Rubolini D., Peacentini D., Brinch C., Spina F., Karlsson L., Stervander M., Andersson A., Waldenström J., Lehikoinen E.A., Edvardsen E., Solvang R. \& Stenseth R.C. 2006. Rapid advance of spring arrival dates in long-distance migratory birds. Science 312: 1959-1961.

Kerr J.T. \& Dobroski S.Z. 2015. Predicting the impacts of global change on species, communities, and ecosystems: it takes time. Global Ecol. Biogeogr. 22: 261-263.

Kundsen E., Linden, A. Ergon T., Jonzén N., Vik J.O., Knape J., Røer J.E. \& Stenseth N.C. 2007. Characterizing bird migration phenology using data from standardized monitoring at bird observatories. Clim. Res. 35: 59-77.

Lawrimore J.H., Menne M.J., Gleason B.E., Williams C.N., Wuerts D.B., Vose R.S. \& Rennie J. 2011. An overview of the Global Historical Climatology Network monthly mean temperature data set, version 3. J. Geophys. Res. 116: D19121. doi:10.1029/2011JD016187.

Lehikoinen E.A., Sparks T.H. \& Zalakevicus M. 2004. Arrival and departure dates. Adv. Ecol. Res. 35: 1-31.

Lehikoinen E.A. \& Sparks T.H. 2010. Changes in migration. In: Møller A.P., Fiedler W. \& Berthold P. (eds) Effects of climate change on birds. Oxford University Press, New York, pp. 89-112.

Lehikoinen, E.A. 2011. Advanced migration of sparrowhawks has increased the predation risk of long-distance migrants of in Finland. PLoS ONE 6:e20001.

Mebs T. \& Schmidt D. 2006. Die Greifvögel Europas, Nordafrikas und Vorderasiens. Franckh-Kosmos, Stugartt.

Mills A. 2005. Changes in the timing of spring and autumn migration in North American migrant passerines during a period of global warming. Ibis 147: 259-269.

Molina B. \& Del Moral J.C. 2005. La Cigüeña Blanca en España: VI censo internacional 2004. Birdlife International, Madrid.

Møller A.P., Fiedler W. \& Berthold P. 2010. Effects of climate change on birds. Oxford University Press, New York.

Newton I. 2008. The migration ecology of birds. Academic Press, London.

Ptaszky J., Kosicki J., Sparks T.H. \& Tryjanowski P. 2003. Changes in the timing and pattern of arrival of the White Stork (Ciconia ciconia) in Western Poland. J. Ornithol. 144: 323-329.

R Development Core Team. 2014. R: a language and environment for statistical computing. R Foundation for Statistical Computing, Vienna.

Sergio F., Tanferna A., de Stephanis R., Jiménez L.L., Blas J., Tavecchia G., Preatonit D. \& Hiraldo F. 2014. Individual improvements and selective mortality shape lifelong migratory performance. Nature 515: 410-413.

Shamoun-Baranes J., van Loon E., Alon D., Alpert P., Yom-Tov Y. \& Leshem Y. 2006. Is there a connection between weather at departure sites, onset of migration and timing of soaring bird autumn migration in Israel? Global Ecol. Biogeogr. 15: 541-552.

Shumway R.H. \& Stoffer D.S. 2006. Time series analysis and its applications: with R examples. Second edition. Springer, New York.

Solomon S., Rosenlof K.H., Portmann R.W., Daniel J.S., Davis S.M., Sanford T.J. \& Plattner G.K. 2010. Contributions of stratospheric water vapor to decadal changes in the rate of global warming. Science 327: 1219-1223.

Thorup K., Tøttrup A.P. \& Rahbek C. 2007. Patterns of phenological change in migratory birds. Oecologia 151: 697-703.

Tøttrup A.P., Thorup K. \& Rahbek C. 2006. Changes in timing of autumn migration in North European songbird populations. Ardea 94: 527-536.

Vaitkuvienė D., Mindaugas D., Bartkevičienè G \& Romanovskaja D. 2015. The effect of weather variables on the White Stork (Ciconia ciconia) spring migration phenology. Ornis Fennica 92: 43-52.

Van Buskirk J. 2012. Changes in the annual cycle of North American raptors associated with recent shifts in migration timing. Auk 129: 691-698.

Vansteelant W.M.G., Bouten W., Klaassen R.H.G., Koks B.J., Schlaich A.E., van Loon E.E. \& Shamoun-Baranes J. 2015. Regional and seasonal flight speeds of soaring migrants and the role of the weather conditions at the hourly and daily scales. J. Avian Biol. 46: 25-39.

Visser M., Perdeck A.C., van Balen J.H. \& Both C. 2009. Climate change leads to decreasing bird migration distances. Global Change Biol. 15: 1859-1865.

Wand M.P. 2014. KernSmooth: functions for kernel smoothing for Wand \& Jones (1995). R package version 2.23-13.

Wand M.P. \& Jones M.C. 1995. Kernel smoothing. Chapman and Hall, London.

\section{SAMENVATTING}

Veranderingen in de fenologie van de trek van vogels wordt gezien als een van de meest in het oog vallende ecologische effecten van klimaatverandering. Er is echter weinig gepubliceerd over veranderingen in trekfenologie van langeafstandstrekkers. Hier wordt een lange tijdreeks van telgegevens uit Zuid-Spanje uit de najaarstrekperiode gebruikt om de mate en richting van een fenologische verandering van zes algemene, van thermiek gebruikmakende soorten te analyseren. De meeste methodes die tegenwoordig worden gebruik om fenologie te onderzoeken, zijn gebaseerd op continue gegevenssets, maar dergelijke gegevens zijn om verschillende redenen vaak niet beschikbaar. Hier wordt gebruik gemaakt van een kruiscorrelatie die het mogelijk maakt om gegevens uit 1999-2011 te vergelijken met gegevens uit 1976-1977. De richting van de verschuiving in tijd van de najaarstrek verschilde tussen de soorten. Ooievaar Ciconia ciconia en Zwarte Wouw Milvus migrans lijken hun trek te hebben verlaat, Zwarte Ooievaar Ciconia nigra en Wespendief Pernis apivorus hebben hun trek vervroegd. Er werd geen verschil gevonden bij Slangenarend Circaetus gallicus en Dwergarend Hieraaetus pennatus.

Corresponding editor: Raymond Klaassen

Received 11 February 2014; accepted 7 January 2016 